\title{
Achieving the Pedagogical Approaches of the Standard-Based Curriculum: Pre-Requisite For Basic School Teachers in Ghana.
}

\author{
1. Clarke Ebow Yalley (Correspondent) \\ Department of Business \& Social Science Education, University of Cape Coast, Ghana, West Africa. Tel: (+233) 0249638774 \\ Email: 3337clarkiss@gmail.com \\ 2. William Jackson Ackon \\ Institute of Education and Planning and Administration, University of Cape Coast, \\ West Africa. Tel: (+233) 0244182385
}

\begin{abstract}
The main purpose of this paper is to provide a conceptual framework that will enable teachers, educators and curriculum experts to be wide-awake to the social constructivist pedagogical approach. This position is to reconceive the social constructivist to a more practical and for easy adaptation by teachers to effectively integrate the social constructivist learning theory and technology/ICT that will encapsulate the "Zone of Proximal Development (Vygotskian theory, 1962) and the "Technological Pedagogical Content Knowledge" (Mishra \& Koehler, 2006) to produce a powerful pedagogue to ensure the delivery of quality education in the attainment of the core competencies of the Standard-Based Curriculum (NaCCA, 2019).

Keywords: Social Constructivism, Technological Pedagogical Content Knowledge, Inclusion, Differentiation and Scaffolding. DOI: $10.7176 / \mathrm{JEP} / 11-1-05$

Publication date: January $31^{\text {st }} 2020$

1.0 Introduction

It is not holistically true that successful people mostly get good opportunities. We are where we are as a result of thought we formed yesterday; this is how our present has been illuminated by our past expeditions. One good thing about the educational reforms and acts is that they do not just emerge from anywhere and anyhow rather they are usually an upgrade of the what is already in existence or has existed based on the assessment and the current happenings within the society. To change our future through the use of education, specifically, through effective and quality teaching and learning, educators or teachers need to think creatively, innovatively, strategically, purposefully and unrestrictedly.
\end{abstract}

In order to permeate through this hurdle, teachers must possess the requisite knowledge which answers the question "What, Why and How?". It is a common believe that knowledge is power but to the researcher knowledge has the value of power but knowledge becomes power only in the hands of those who think creatively and purposefully through the knowledge they possess to solve personal and societal problems. As teachers, we need to possess the knowledge of "what to teach", "why teaching that particular topic" and finally "how to go about the topic to be taught?". These set of probing questions turn to find out the content, the purpose and the pedagogy teachers deploy in their teaching and learning processes which are the underlining principle of the Standard Based Curriculum (NaCCA, 2019; MoE, 2019). To fully achieve the intended purpose of the Standard Based Curriculum, teachers need to articulate the theory of learning that is applicable to the context of teaching their students. Also, teachers must know, articulate and justify the creative pedagogy appropriate for teaching a particular content (theory and approach of teaching).

Among the most stimulating questions and educational reforms that have risen over the years on the competencies of teachers boils down to the relationship between teaching and learning. Gauging from the educational reforms, can there be teaching if there is no kind of definable learning? When and how is teaching most powerfully enacted? And who or what is most responsible for learning: the teacher, the learner, or the environment? The answer to these questions, is hoped to lead to the recommendations for the positioning of "Social Constructivism" as a pedagogical approach with ICT/technology serving as a means to scaffold the learning of students. Hillocks (1999) and Nystrand et al. (1997) are of the view that teachers usually hold implicit theories about teaching and learning that inform their planning and their day-to-day decision making. Yet, these theories are typically underarticulated, unrecognized, underspecified, and quite inconsistent if not schizophrenic in their application.

It is the contention of the researcher that clearly stating and coming to understand one's theory (or theories) about teaching and learning can help us to develop a coherent instructional model and then to scrutinize, converse about and adapt our teaching in ways that hold powerful benefits for teachers and learners. All these competencies and skills to maneuver efficiently and effectively depends on the competencies of the teacher which includes but not be limited to the teacher's content knowledge, teacher's pedagogical knowledge, teacher's technological knowledge and teacher's knowledge of the learners (Shulman, 1867; Mishra \& Koehler, 2009). The Standard-Based Curriculum as well encourages the use of Information and Communication Technologies (ICTs) a tool for teaching and learning (NaCCA, 2019). The Ministry of Education of Ghana endorses a quality learning experience as an entitlement for each of Ghana's school-going girl and boy; the curriculum has rightly focused on learning and learning progression (MOE, 2019). By implication, the new curriculum focuses on the learning-centered and preparing students to become a lifelong - learning individuals. These broad goals of the teaching and learning philosophies of the Standard-Based Curriculum can only be achieved if teachers possess the competencies, skills and the knowledge needed to teach simple things creatively and constructively to generate quality learning among learners. For this evolution to succeed, teachers must be wide-awake to their teaching and learning theories in order to lend learners their expertise and support 
(Maxine, 1978). This paper is to reconceive the social constructivist to a more practical and for easy adaptation by teachers to ensure the delivery of quality education in the attainment of the core competencies of the Standard-Based Curriculum (NaCCA, 2019).

\subsection{Significance of the Paper}

In view of the researchers, this position paper will provide a conceptual framework that will enable teachers, educators and curriculum experts to be wide-awake to the social constructivist pedagogical approach. As change is difficult to accept, this position paper will serve as a malleable milieu where Basic School teachers and educators will possess the epistemology of the step by step process of effectively integrating the social constructivist learning theory and technology/ICT which will encapsulate the "Zone of Proximal Development (Vygotskian theory, 1962) and the "Technological Pedagogical Content Knowledge" (Mishra \& Koehler, 2009) to produce a powerful pedagogue. Moreover, a careful analysis of the above significance will bring to light how each of the independent pedagogical approaches (learning-centred classroom, teachercentred schools, ICT usage as a tool for teaching and learning, inclusion, differentiation and scaffolding) as stipulated in the Standard-Based Curriculum can be applied within the Social Constructivism pedagogue of teaching and learning. In addition, this review will contribute to the nationwide acceptability and adaptation of the theoretical framework "Social Constructivism" pedagogy by Lev Semyonovich Vygotsky as an effective teaching and learning pedagogy for educating students to possess the competencies of the $21^{\text {st }}$ century world.

\subsection{LITERATURE REVIEW}

The National Curriculum Framework (NPCF) is a guiding document that provides policy direction to the review and implementation of the pre-tertiary curriculum. Also, it draws together and articulates the vision, philosophy, goals, learning experiences, instructional resources and assessment systems that will guide the development of the school curriculum. It as well goes a long way of providing the basis for consistent and on-going curriculum development, implementation and periodic curriculum review and revision (NaCCA, 2019). According to the National Council for Curriculum and Assessment (NaCCA) (2019) the rationale for reviewing the Objective-Based curriculum was to respond to a national priority of shifting the structure and content of the education system from merely passing examinations to building character, nurturing values, and raising literate, confident, and engaged citizens who can think critically.

Conferring to the National Council for Curriculum and Assessment (NaCCA) (2019), the pedagogical approach stipulated in the Standard Based Curriculum for Basic schools' teachers to employ within their teaching and learning process in Ghana are: Social constructivist; Learning-centred teaching; Teaching-centred schools; Inclusion; Scaffolding; and Differentiation. These pedagogical approached are earmarked towards the attainment of six essential core competencies (Communication and collaboration; critical thinking and problem solving; creativity and innovation; cultural identity and global citizenship; leadership and personal development and digital literacy) (NaCCA, 2019).

After attaining political independence from Great Britain in 1957, Ghana has embarked on massive educational reforms to meet her contemporary educational needs. Despite the numerous efforts by the past government to revamp education to meet modern challenges, there were still persistent problems affecting the policy initiative due to poor teaching and learning pedagogical adaptation (MoE 2019). It is from this milieu that the present study reviews literature (theoretical and conceptual) to provide a step by step process of implementing the social constructivism pedagogical approach of teaching and learning within the educational sectors of my country "Ghana".

\subsection{Theoretical and Conceptual Framework}

There are many summaries of research on teaching and learning approaches that have been accepted by many as paradigms of effective practices. Independent of each other, this position paper will present the Vygotskian theory "Zone of Proximal Development (1962) and the "Technological Pedagogical Content Knowledge" by Mishra and Koehler (2009) as the theoretical framework and as well integrate these two heterogeneous theories to develop a conceptual framework that will favor a more practical step by step usage of ICT within the social constructivist theory of teaching and learning.

\subsubsection{Vygotsky's Theory of Cognitive Development}

The goal of the constructivist philosophy is to ensure active exploration, construction and learning and motivates the students to seek new knowledge and skills because they need them in order to solve a problem at hand. This approach of teaching and learning becomes "problem-based" and learning-centered approach where a life-long learning habit is inculcated in the student.

Lev Vygotsky believed that knowledge is first constructed in a social context and collaborated with other individuals or groups. This is known as "Social Constructivism". Vygotsky believed children's thinking is affected by their knowledge of the social community (which is learnt from either technical or psychological cultural tools) (Vygotsky, 1978). He also suggested that language is the most important tool for gaining this social knowledge. The major theme of Vygotsky's theoretical framework is that social interaction plays a fundamental role in the development of cognition. The social cognition-learning model asserts that culture is the prime determinant of individual's development. Humans are the only species to have created culture, and every human child develops in the context of a culture. Therefore, a child's learning development is affected in ways large and small by the culture including the culture of family environment in which he or she is ensnared. Vygotsky's theory is one of the foundations of constructivism. It asserts three major themes:

1. Social interaction plays a fundamental role in the process of cognitive development. In contrast to Piaget's understanding of child development, Vygotsky felt social learning precedes development. He states: "every 
function in the child's cultural development appears twice: first, on the social level and later on the individual level: first, between people (inter psychological) and then inside the child (intra psychological) (Vygotsky, 1978).

2. The More Knowledgeable Other (MKO). The MKO refers to anyone who has a better understanding or a higher ability level than the learner, with respect to a particular task, process or concept. The MKO is normal thought of as being a teacher, coach or older adult but the MKO could also be peers, a young person or even a computer. This MKO is what the National Council for Curriculum and Assessment refer to as the teacher-centred schools and a facilitator.

3. The Zone of Proximal Development (ZPD). The ZPD is the distance between a student's ability to perform a task under adult guidance and or with peer collaboration and the student's ability solving the problem independently.

According to Vygotsky, learning occurs at this zone. The Zone of Proximal Development is a key feature of this theory. There are two levels of attainment for the ZPD:

1. Level 1: The present level of development'. This describes what the child is capable of doing without any help from others.

2. Level 2: The 'potential level of development'. This means what the child could potentially be capable of with help from other people or 'teachers.

The gap between level 1 and 2 (the present and potential development) is what Vygotsky described as this Zone of Proximal Development. He believed that through help from other, more knowledgeable people (facilitator), the child can potentially gain knowledge already held by them. However, the knowledge must be appropriate for the child's level of comprehension. Anything that is too complicated for the child to learn that isn't in their ZPD cannot be learnt at all until there is a shift in the ZPD. When a child does attain their potential, this shift occurs and the child can continue learning more complex, higher level material.

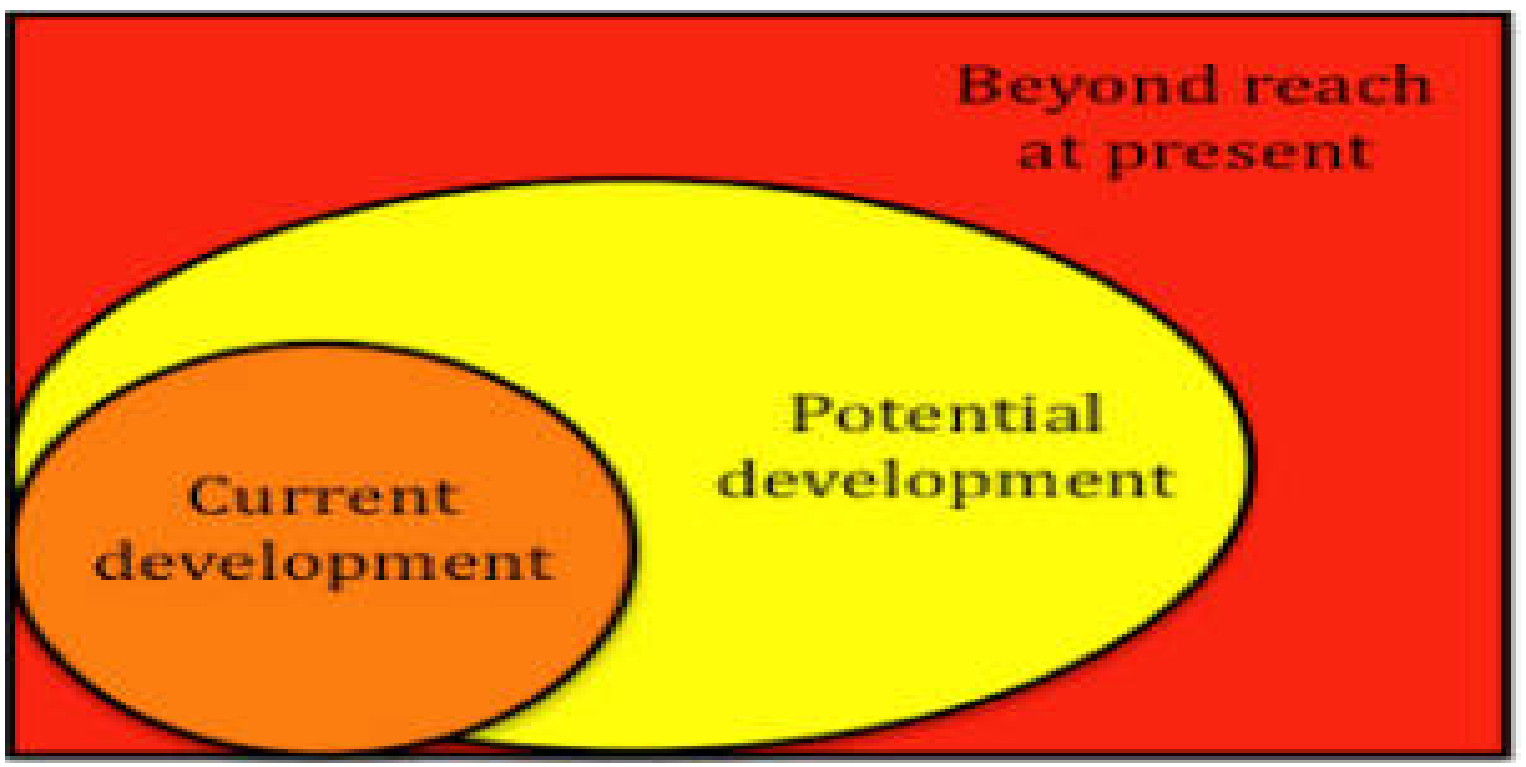

Vygotsky viewed the ZPD as a way to better explain the relation between children's learning and cognitive development. Prior to the ZPD, the relation between learning and development could be boiled down to the following three major positions:

1. Development always precedes learning (e.g., constructivism): children first need to meet a particular maturation level before learning can occur.

2. Learning and development cannot be separated but occur simultaneously (e.g., behaviorism): essentially, learning is development.

3. Learning and development are separate but interactive processes (e.g., gestaltism) one process always prepares the other process, and vice versa 
Vygotsky rejected these three major theories because he believed that learning always precedes development in the ZPD. In other words, through the assistance of a more capable person 'the facilitators', a child is able to learn skills or aspects of a skill that go beyond the child's actual developmental or maturational level. Therefore, development always follows the child's potential to learn. In this sense, the ZPD provides a prospective view of cognitive development, as opposed to a retrospective view that characterizes development in terms of a child's independent capabilities.

Scaffolding is a concept closely related to the idea of ZPD, although Vygotsky never actually used this term. Scaffolding is changing the level of support to suit the cognitive potential of the child. He believed that when a student is at the ZPD for a particular task, providing the appropriate assistance (scaffolding) will give the student enough boost to achieve the task. Once the learner, with the benefit of scaffolding, masters the task, the scaffolding can then be removed and the student will then be able to complete the task again on his own. Over the course of a teaching session, one can adjust the amount of guidance to fit the child's potential level of performance. More support is offered when a learner is having difficulty with a particular task and, over time, less support is provided as the child makes gains on the task. Ideally, scaffolding works to maintain the child's potential level of development in the ZPD. In a dialogue, a learner's unsystematic, disorganized, and spontaneous concepts are met with the more systematic, logical and rational concepts of the skilled helper (Vygotsky, 1962).

Gauging from the importance of scaffolding, it is imperative to differentiate learners either by task, by support or by outcome. Also, learners can be differentiated based on level of learner in the class that is by higher fliers, average learners and slow learners. Furthermore, the learners can be differentiated by their emotional intelligence level.

In addition, learners can be differentiated by their motivational level that is are learners internally motivated to learn or need external motivation to learn. In order for teaching to benefit all learners, there is often the need to structure for both heterogeneous classes (consisting of learners of unequal or mixed abilities) and homogeneous class (learners with similar challenges or equal abilities). Ideally, quality instruction must serve each student according to their special needs, learning styles and interest.

As differentiation has highlighted to learners who need assistance/scaffold, MKO will render his /her professional assistance and scaffold to the learners. As the MKO (facilitator) is rendering professional assistance, he is ensuring inclusivity within the teaching and learning episode thus "One Child Left Behind"). Furthermore, it is through differentiation that the teacher/facilitator determines which session of the learners need remediation (weak learners) and those that need acceleration (higher ability learners) (Haffar, 2018).

\subsubsection{Technological Pedagogical Content Knowledge by Mishra \& Koehler (2006)}

The need for teachers to use technology during their instructional period appears to be a key component in almost all perfection plans for education and educational transformation programs (Davis \& Falba, 2002; Dawson, Pringle, \& Adams, 2003; International Society for Technology in Education, 2002; Thomas, 1999; Thompson, Schmidt, \& Davis, 2003). According to Gess-Newsome, Blocher, Clark, Menasco, and Willis (2003), while some issues in education take on the flavour of their social and historical context, some others, such as how to train teachers to integrate technology in teaching instruction linger almost perennial and ill-defined.

With the current modernization of education, Mishra and Koehler (2006) have introduced technology to Shulman's (1987) "Knowledge Domain" to bring the framework "Technological Pedagogical Content Knowledge (TPACK)", an educational research field for understanding teacher knowledge for effective technology integration in the teaching and learning process. Integrating teachers' content knowledge (CK), pedagogical knowledge (PK) brings up pedagogical content knowledge (PCK) whiles the integration of technology to PCK develops Technological Pedagogical Content Knowledge (TPCK) which will produce a multifaceted and dynamic classroom context (Yalley, 2017). 
Technological Pedagogical Content Knowledge Framework

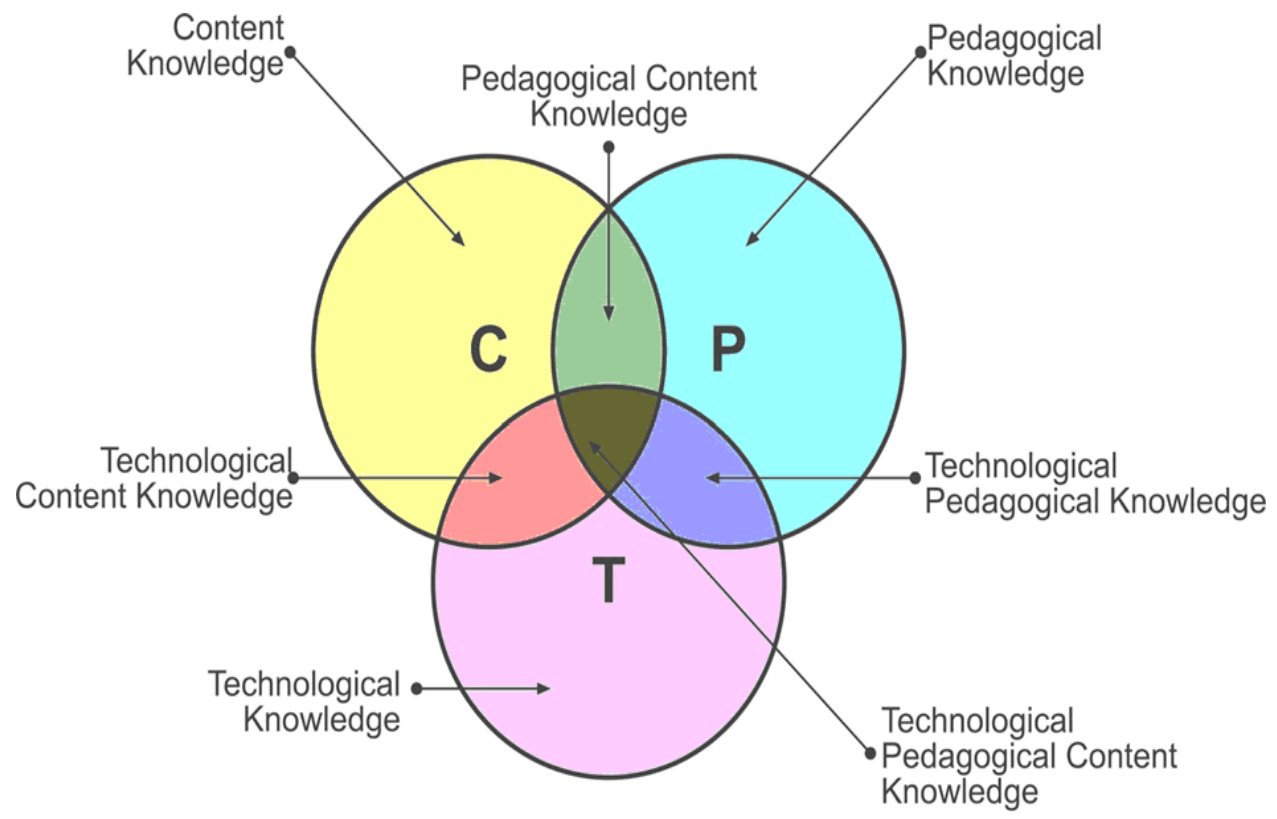

Figure 1: An Illustration of the TPCK Model by Mishra and Koehler (2006)

The researcher has applied Mishra and Koehler (2006) theory by extending it to the phenomenon of Basic School teachers' integration of technology into content and pedagogy for effective and efficient teaching and learning of their subjects. This implies that any teacher who wants to integrate technology in their teaching practices should be competent in all the three domains. If teachers are to be successful, they need to confront the issue of technology, content and pedagogy simultaneously.

Effective technology integration is achieved when its used to support curricular goals. It must support four key components of learning: active engagement, participation in groups, frequent interaction and feedback, and connection to real-world experts (Harkverdi, Gucum, \& Korkmaz, 2007). It has been widely agreed that instructional technology does, indeed hold a remarkable promise for changing the quality of teaching and learning in schools - it is the catalyst for transformation (Ryan \& Cooper, 2006; Honey, 2001). With so many different forms of technology available to be used and integrated into the classroom, how can teachers know which strategies are the most effective? Some of the latest and hottest trends being used to integrate technology curriculum are:

i. Virtual or online field trips,

ii. WebQuests,

iii. Educational games online

iv. Computer simulation programs,

v. Digital poster website,

vi. $\quad$ Glogster (Ayas, 2006).

It is also important to track the various stages of technology integration by teachers. Association for Educational Communication and Technology (2004) made a major contribution in this area by identifying five stages teachers pass through:

1. Entry - where teacher uses technology to deliver curriculum content to students;

2. Adoption - where teacher directs students in the conventional use of tool-based software;

3. Adaptation - where teacher encourages students to select a tool and modify its use to accomplish the task at hand;

4. Infusion - where teacher consistently provides for the infusion of technology tools with understanding, applying, analyzing, and evaluating learning tasks; and

5. Transformation - where teacher blends technology tools with student-initiated investigations, discussions, compositions, or projects across any content area. 


\subsection{Conceptualization of Vygotskian theory "Zone of Proximal Development (1962) and the "Technological Pedagogical Content Knowledge" by Mishra and Koehler (2006)}

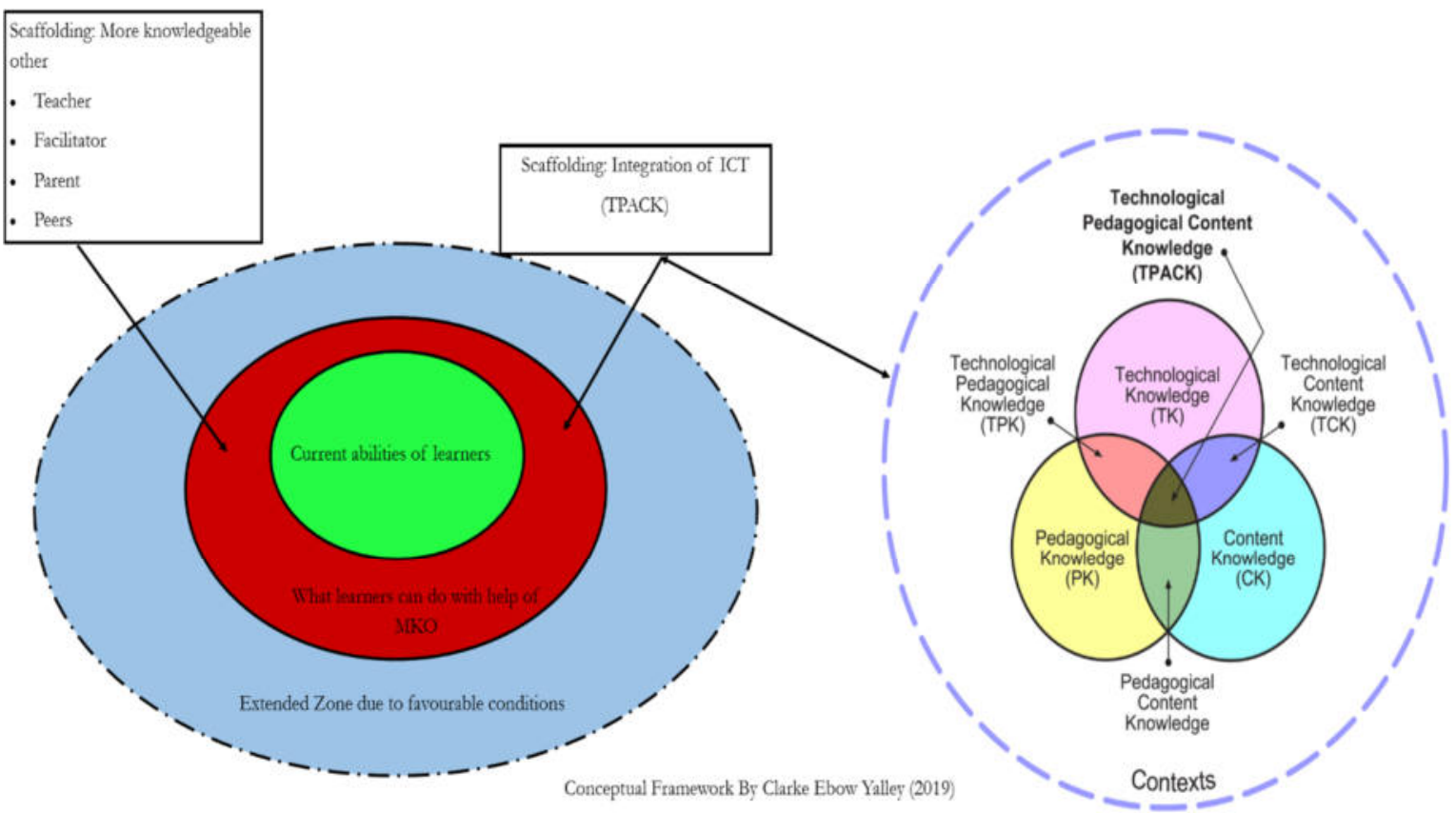

For clarity of importance attached to the various level of the social constructivist theory of learning, the green represents the already possessed knowledge, skills and competencies of the learner. The learner is seen as a green leaf who needs attention, assistance and guidance to blossom. The red represents the crucial or critical region of the learner. The need for scaffolding from a more knowledgeable other (teacher, facilitator, parent or the peer) can render valuable assistance to the learner. Due to the difference in learners' abilities, learning assimilation and accommodation and learner exposure to technological knowledge it is imperative to scaffold learners with a technological approach. Through the use of technology integrated teaching and learning, the various senses to which learners learn will be captured, interest of learners regained, experience of learners exploited and a link of concept, skills and knowledge to real life experience (authentic task of learning).

Learning is the province of the learners, who must necessarily construct their own understandings. Knowledge is acquired by learners in the process of their self-initiated inquiries and personal investigations. Again, it is the learner who is responsible; no one else can "do" learning for them and their achievement of new knowledge requires active involvement and personal exploration. As Vygotsky suggests, it involves both active learners and more expert partners, usually (adult/facilitator) who will provide leadership and assistance to the less skilled learners as they engage together in a community of practice. Introducing the concept of ZDP within the learning zone, learners are assisted in a variety of ways to achieve their goal of learning. Within the $21^{\text {st }}$ century, technology is within the continuum of learners and forms majority of their experiences to which the MKO can tap to render the needed assistance and guidance needed to liberate the learner to the next learning ladder.

\subsection{Where learners learning take place by the Social Constructive Theory}

It can be deduced from the theories and concepts reviewed that when a task, test or an assignment is given to a learner which the learner independently complete such task without the help or assistance from any other person, such learner has not learnt anything. Invariably, the precious and valuable time of the learner has been wasted because such knowledge is already within the learners Zone of Actual Development (ZAD) (Vygotsky, 1962). Gauging from the above assertation, the place where instruction and learning can take place is the Zone of Proximal Development (ZPD). Learning occurs in this cognitive region, which lies just beyond what the learner can do alone but rather needs the assistance and support of a more knowledgeable person (teacher, facilitator, parent, a peer) is where learning actually takes place (Wood, 998). Here, the already internalized knowledge of the learner is built upon to advance to the next learning stage or ladder. The learner's new capabilities can only be developed in the ZPD through collaboration in actual, concrete, situated activities with a more capable person. More importantly, with adequate assisted and guided practices through the use of "I do you watch" to "I do you help" to You do I help" to You do I watch" (I represent the MKO" and the "You represent the learner) where this phenomenon leads to the assimilation and the accommodation of the new capabilities, competencies, skills and knowledge and concepts of the learner's psychology and personal problem-solving repertoire (Driscoll, 1994). Finally, it is when this is achieved that learning practically takes place in the intellectual capacity of the learner. Thus, these new capabilities, competencies, skills and knowledge and concepts enters the learner's Zone of Actual Development (ZAD) for another build up in the quest of finding new knowledge and skills. 


\subsection{Application of the Vygotsky's Social Development to Standard-Based Curriculum of Ghana's Education}

1. 1. A contemporary application of Vygotsky's theories is "reciprocal teaching", used to improve learner's ability to learn from text. In this method, teachers and students collaborate in learning and practicing four key skills: summarizing, questioning, clarifying, and predicting. The teacher's role in the process is reduced to a facilitator or a guide to the learners as learner move higher the learning paddle over time.

2. The appropriate teaching and learning approach is the learner-centred approach.

3. Teaching and learning instruction should be from known to the unknown or from concrete to abstract or from simple to complex. This enables learners to learn using the experiential approach.

4. The facilitator must have adequate knowledge about his/her learners

5. Teaching and learning should lay emphases on discovery learning thus learning that helps in solving societal problems.

6. Learner must construct/develop their knowledge through active participation in their learning based on their previous experience.

7. Teacher should build student background knowledge through various learning experiences (e.g., field trips, multimedia presentations, historical fiction, technology, community resource people).

8. Learning should be focused on building concepts, skills and competencies that can set the learners on a life-long learning mood.

9. Facilitator links concepts and key ideas to learners' prior experiences and understandings, uses multiple representations, examples and explanations.

10. Teacher incorporates student experiences, interests and real-life situations in instruction. The teacher:

i. Implements lessons that include students and teachers local and personal histories.

ii. Stimulates students to investigate and respond to human condition in the contemporary world.

iii. Encourages students to consider multiple perspectives and share their point of view, values and beliefs.

11. Teacher makes lesson connections to community, society, and current events. The teacher:

i. Encourages students to be involved in service-learning projects.

ii. Utilizes the experience and expertise of a variety of community resource people.

iii. Connects learning to community, society, current events, multiple points of view and global perspectives.

iv. Encourages students to develop a commitment to social responsibility, justice, action, citizenship, civic values and reflective concern for the common good.

12. Teacher accesses a rich repertoire of instructional practices, strategies, resources and applies them appropriately.

13. It is through these assessment mediums that the various and different learning difficulties and learning barriers can be identify for appropriate scaffolding/assistance be given to learners to enable the learners progress to the next learning stage

14. Facilitator designs learning opportunities that allow learners to participate in empowering activities in which learners understand that learning is a process and mistakes are naturally part of the learning.

15. In the application of the social constructivist theory, assessment of learners learning progression is key. This assessment will take of diagnostic and formative assessment. For the formative assessment, assessment for learning (centred on the facilitator) and assessment as learning (centred on the learner).

16. Facilitators are expected to administer and employ different assessment techniques assessing their learners. This assessment becomes comprehensive in nature which covers all aspect of the learners learning. These assessments should be done at intervals as the learning unfolds.

17. The assessment must be systematic in nature in the sense that it requires an operational plan, namely the measurement to be made, at what period, taking and filling of records of the progress of the learner.

18. Teacher selects and utilizes a variety of technology that support student learning.

19. In the course of scaffolding learners, it is imperative for facilitators to integrate ICT as a teaching and learning pedagogy. By this the facilitator should be knowledgeable and should possess the competencies for integrating the content of the subject, the pedagogy and the technology into a powerful learning missal.

20. By the integration of ICT into the teaching and learning process, the facilitator meets the learning needs and the divergent medium of learning of learners that is the auditory learners, the visual learners and auditory-visual learners.

21. Teacher must participate and contributes to professional learning communities (PLC) (a method to foster collaborative learning among colleagues within a particular work environment or field, e.g., workshops, seminars and symposia).

\subsection{Recommendation}

It is envisaged that this paper will enable teachers, educators and curriculum experts to be wide-awake to the social constructivist pedagogical approach. As change is difficult to accept, this position paper will serve as a malleable milieu where Basic School teachers and educators will possess the epistemology of the step by step process of effectively integrating the 
social constructivist learning theory and technology/ICT which will encapsulate the "Zone of Proximal Development (Vygotskian theory, 1962) and the "Technological Pedagogical Content Knowledge" (Mishra \& Koehler, 2009) to produce a powerful pedagogue. Also, it is recommended that this paper will bring to light how each of the independent pedagogical approaches (learning-centred classroom, teacher-centred schools, ICT usage as a tool for teaching and learning, inclusion, differentiation and scaffolding) as stipulated in the Standard-Based Curriculum can be applied within the Social Constructivism pedagogue of teaching and learning by Basic School teachers and educators in Ghana.

\subsection{Conclusion}

He who aims at excellence will be above mediocrity; who aims at mediocratic will be far short of it. Also, in learning, age and youth go for nothing; the best-informed (MKO) takes the precedence. It is envisaged that Basic School Teachers in Ghana will advance their knowledge, skills and competencies to meet this new change of the "Standard-Based Curriculum" to ensure effective facilitation and quality learning among learners. It is recommended that teachers should adapt this process and continuously deploy this process to gain mastery of this conceptual process of integrating these two heterogeneous theories to develop a conceptual framework that will favor a more practical step by step usage of ICT within the social constructivist theory of teaching and learning. In all, knowledge is socially and culturally constructed and that "the what and how" the learners learn depend on what opportunities the More Knowledgeable Other (MKO) that is the facilitator provides during the instructional period.

\section{REFERENCES}

Association for Educational Communications and Technology. (2004). The meaning of educational technology. Definition and Terminology Committee, Bloomington. Available at http://ocw.metu.edu.tr/file. Php /118/ molenda _ definition. pdf. Retrieved on January 29, 2014

Ayas, C. (2006). An examination of the relationship between the integration of technology into social studies and constructivist pedagogies. The Turkish Online Journal of Educational Technology, 5(1), 64-72

Crawford, K. (1996). Vygotskian approaches to human development in the information era. Educational Studies in Mathematics. (31) 43-62.

Davis, K. S., \& Falba, C. J. (2002). Integrating technology in elementary pre-service teacher education: orchestrating scientific inquiry in meaningful ways. Journal of Science Teacher Education, 13(4), 303329.

Dawson, K., Pringle, R., \& Adams, T. L. (2003). Providing links between technology integration, methods course and schoolbased field experience: A curriculum-based and technology-enhanced microteaching. Journal of Computing in Teacher Education, 20(1), 4147.

Driscoll, M. P. (1994). Psychology of Learning for Instruction. Needham, MA: Allyn \& Bacon.

Haffis, A. (2018). Strategies for effective teaching and learning. Marcel Hug

Gess-Newsome, J., Blocher, J. M., Clark, J., Menasco, J., \& Willis, E. M. (2003). Technology infused professional development: A framework for development and analysis. Contemporary Issues in Technology and Teacher Education, 3(3), 324-340.

Harkverdi, M., Gucum, B., \& Korkmaz, H. (2007). Factors influencing pre-service science teachers' perception of computer self-efficacy. Asia-Pacific forum on Science Learning and Teaching, 8(1), Article 13.

Honey, M. (2001). Technology's effectiveness as a teaching and learning tool. Testimony and statement for the record before the Labour, HHS, and Education. Appropriations Subcommittee of the U.S. Senate. Education Development Centre, Inc. Retrieved fromhttp://www.edc.org/spotlight/Tech/mhtestimony.htm.

International Society for Technology in Education (2002). National educational technology standards for teachers: Preparing teachers to use technology. Eugene, OR: International Society for Technology and Education.

National Council for Curriculum and Assessment (2019). Resource guide for the orientation of primary school teachers towards the implementation of the revised curriculum for primary schools. Accra. Ministry of Education.

Mishra, P., \& Koehler, M. J. (2006). Technological pedagogical content knowledge: A framework for teacher knowledge. Teacher's College Record, 108(6), 1017-1054.

Ryan, K., \& Cooper, J. (2006). Those who can, teach. (14th ed.). Boston, MA: Cengage Learning.

Shulman, L. (1986a). Those who understand: knowledge growth in teaching. Educational researcher, 15(2), 4-14.

Shulman, L. S. (1986b). Paradigms and research programs in the study of teaching: A contemporary perspective. In M. C. Wittrock (Ed.), Handbook of research on teaching. ( $3^{\text {rd }}$ ed.). New York, NY: Macmillan.

Shulman, L. S. (1987). Knowledge and teaching: Foundation of the new reform. Harvard Educational Review, 57(1), 1-22.

Thompson, A. D., Schmidt, D. A., \& Davis, N. E. (2003). Technology collaborative for simultaneous renewal in teacher education. Educational Technology Research and Development, 5(9), 124-128

Vygotsky, L. S. (1962). Thought and Language (1934), trans. Eugenia Hanfmann and Gertrude Vokar. Cambridge, MA: MIT Press.

Vygotsky, L. S. (1978). Mind in Society: The Development of Higher Psychological Processes, ed. James V. Wertsch. Cambridge: Harvard University Press. 
Wood, David. (1998). How Children Think and Learn: The Social Contexts of Cognitive Development, (2nd ed). Malden, MA: Blackwell Publishers.

Wertsch, J. V., Sohmer, R. (1995). Vygotsky on learning and development. Human Development. (38 )332-37.

Yalley, C. E. (2017). Investigating the technological pedagogical content knowledge of Social Studies teachers in the senior high schools in the Kumasi metropolis of Ghana. Journal of Education and Practice, 8(4), 102-110 